\title{
Psychiatric understanding and treatment of patients with amputations
}

\author{
So-Hye Jo ${ }^{1}$, Suk-Hun Kang ${ }^{1}$, Wan-Seok Seo ${ }^{2}$, Bon-Hoon Koo ${ }^{2}$, Hye-Geum Kim ${ }^{2}$, Seok-Ho Yun ${ }^{1}$ \\ ${ }^{1}$ Department of Psychiatry, Yeungnam University Hospital, Daegu, Korea \\ ${ }^{2}$ Department of Psychiatry, Yeungnam University College of Medicine, Daegu, Korea
}

Received: February 20, 2021

Revised: March 26, 2021

Accepted: April 2, 2021

Corresponding author:

Suk-Hun Kang, MD, PhD

Department of Psychiatry,

Yeungnam University Hospital, 170

Hyeonchung-ro, Nam-gu, Daegu

42415, Korea

Tel: +82-53-620-3345

Fax: +82-53-657-3921

E-mail: gowkdwltjs@naver.com
Amputation changes the lives of patients and their families. Consequently, the patient must adapt to altered body function and image. During this adaptation process, psychological problems, such as depression, anxiety, and posttraumatic stress disorder, can occur. The psychological difficulties of patients with amputation are often accepted as normal responses that are often poorly recognized by patients, family members, and their primary physicians. Psychological problems can interfere with rehabilitation and cause additional psychosocial problems. Therefore, their early detection and treatment are important. A multidisciplinary team approach, including mental health professionals, is ideal for comprehensive and biopsychosocial management. Mental health professionals could help patients set realistic goals and use adaptive coping styles. Psychiatric approaches should consider the physical, cognitive, psychological, social, and spiritual functions and social support systems before and after amputation. The abilities and limitations of physical, cognitive, psychological, and social functions should also be considered. To improve the patient's adaptation, psychological interventions such as short-term psychotherapy, cognitive behavioral therapy, mindfulness meditation, biofeedback, and group psychotherapy can be helpful.

Keywords: Amputation; Psychological intervention; Psychological stress; Psychosomatic medicine

\section{Introduction}

Amputation is an event that has a dramatic effect on an individual's life and is common in modern society. Although the frequency of amputation is expected to decrease because of the development of medical treatments and the decrease in the incidence of injuries, a certain number of cases are expected to remain owing to the aging population, diabetes, and peripheral vascular disease [1]. Furthermore, the number of amputated patients is expected to increase. In the United States, approximately 185,000 amputations are performed annually, and by 2050 , the number of people with amputations is expected to reach 3.6 million, more than double the number in 2005 [2]. In Korea, there is still a lack of detailed and accurate statistics on the frequency of amputation. According to a 2017 survey of the disabled by the Ministry of Health and Welfare, physical disability (48.1\%) accounted for the largest proportion of all types of disabilities as of 2018 , with $14 \%$ of these people having amputations [3].

Amputation is both a physical disability and a psychological emergency. It leads to impairment of an individual's physical function, sensation, and body image, and causes intense and diverse emotional responses [4]. Patients may feel as if they have experienced death beyond the meaning of physical loss. In particular, those with trauma-related amputations may be greatly shocked by the unprepared loss and experience greater difficulties in adapting. Therefore, patients in these cases require a more delicate evaluation and treatment of psychiatric problems.

Patients with amputation have been found to experience anxiety,

Copyright (C) 2021 Yeungnam University College of Medicine

This is an Open Access article distributed under the terms of the Creative Commons Attribution Non-Commercial License (http://creativecommons.org/licenses/by-nc/4.0/) which permits unrestricted non-commercial use, distribution, and reproduction in any medium, provided the original work is properly cited. 
depression, and posttraumatic stress disorder due to loss and self-stigmatization [5]. Depressive symptoms are common in the first 2 years after amputation, and depression and anxiety may increase again during adjustment to daily life after discharge $[6,7]$. In a previous study on patients with traumatic amputation, $35 \%$ experienced depression and $60 \%$ experienced anxiety in the first 6 months after amputation [8]. Of them, $83 \%$ received psychiatric treatment, but only $10 \%$ continued treatment 2 years later. As such, there is a need to care for psychiatric problems in amputated patients. However, there is still a lack of psychiatric understanding and effective treatment for them.

Ideally, the mental health of amputated patients should be properly managed throughout the entire process of returning to daily life, even before amputation. However, clinically, it is often difficult to see them in an outpatient consultation setting until the amputee complains of psychological problems. Sometimes, anxiety or depression after amputation is accepted as a normal reaction, which may not be well recognized by patients, families, or primary doctors. Early detection and treatment of psychological problems are important for enhancing the lives of patients and preventing derived psychosocial problems [9].

Mental health professionals can improve psychological adaptation by normalizing the patient's emotions and experiences related to amputation and helping the patient use adaptive coping mechanisms. Mental health professionals also play a role in promoting communication and encouraging patients and therapists within a multidisciplinary team treatment. For mental health professionals to perform these roles, an in-depth understanding of the psychological characteristics of patients with amputation is essential. However, psychological characteristics and outcomes of patients with amputation are mainly being studied in the industrial field, and even within the department of psychiatric medicine, only a few are dealt with psychosomatic medicine and consultation-liaison psychiatry.

Despite many advances in the field of prosthesis, there are not many systematic studies on mental health or the effects of psychological interventions on amputated patients. Therefore, in this study, we aimed to understand the experience of amputated patients from deciding to perform an amputation in their daily lives and to determine the effect of amputation on a patient's mental health. In addition, as psychiatrists, we intend to contribute to further research to improve mental health by identifying special considerations and applicable psychological treatments for patients with amputation.

\section{Characteristics of amputation}

\section{Causes of amputation}

The most common cause of amputation is peripheral vascular disease (75\%), often seen in patients with diabetes and vasculitis. The second most common cause of amputation is trauma, followed by infection, tumors, nerve damage, and congenital malformations. Amputation of the upper limb is often caused by trauma, and amputation of the lower limb is often caused by peripheral vascular disease [1].

\section{Sex}

Amputation rates are higher in men than in women. Men who work with machines are at especially high risk of amputation; $87 \%$ of patients with trauma are male, of whom $80 \%$ are in their 40 s [10]. While amputation rates in women are lower than in men, there are many amputations related to more serious medical conditions, which tend to lead to worse recovery than that for men [11]. Moreover, women are more susceptible to postamputation depression than men [12].

\section{Age}

Children may be sensitive to the acceptance and rejection of their peers, but they generally adapt relatively well [13]. Family cohesion and social support play important roles in positive adaptation after amputation in children [14]. However, adolescents tend to experience difficulties adapting to amputation. They may feel that amputation is a great threat to body image, sexual identity, peer relationships, and autonomy [15]. Adolescents feel sad and become dependent, but ultimately undergo a process of accepting the changes in their physical appearance and return to the social system [16]. There are reports that older adults experience more emotional difficulties, such as depression or adjustment problems, but the results are not consistent between studies $[17,18]$. In contrast, studies have shown that the risk of emotional difficulties is low because of reduced basic activities and better acceptance of physical limitations [19].

\section{Site of amputation}

Upper limb amputation is more frequently associated with posttraumatic stress disorder and depression than lower limb amputation [20]. This is because the upper limb plays a greater role in self-expression, self-care, and communication, resulting in more functional loss than lower extremity amputation. In the case of lower extremity amputation, above-the-knee amputation generally leads to poorer functional results than below-knee amputation [21]. 


\section{Pain}

Approximately 50\%-95\% of patients with amputation experience chronic pain [22]. Pain includes residual limb, non-amputated limb, and phantom limb pain. In amputated patients, phantom limb pain has a 50\%-80\% incidence and often does not respond well to treatment, which reduces the quality of life [23,24]. Chronic pain is associated with difficulties in psychosocial adaptation and unemployment [25].

\section{Employment}

Returning to work is affected by various factors such as age, vocational ability before amputation, level of amputation, social support, and the national disability system [5]. Patients who live with physical skills are more vulnerable to negative emotional reactions. It takes an average of 1 year to return to work, and more than half of patients with amputation tend to return to work within 2 years $[26,27]$. Among patients with traumatic amputations, more of them remain unemployed if diagnosed with depression [28].

\section{Psychological reactions and changes after amputation}

After amputation, psychological difficulties may occur because of altered perceptions and distorted body image of oneself. The belief that they will be considered incomplete is painful. When patients have difficulty accepting new body image and social stigma, their vulnerability is stimulated, and it is easy to use non-adaptive coping mechanisms $[29,30]$. In addition, amputation can cause problems of sexual function as well as changes in body image, and these factors can cause psychological difficulties, such as depression and anxiety, problems of adaptation, and lowered quality of life [31]. Factors affecting psychological reactions after amputation include age, personality traits, coping skills, flexibility, social support, comorbid physical illness, and the cause of amputation [32]. Also, psychological reactions can appear in various ways, depending on individual personality characteristics. For patients with narcissistic personality traits, amputation can be considered a great attack on self-worth and dignity. Conversely, those with dependent personality traits may welcome the patient role and may be relieved from preexisting responsibilities and pressures.

\section{Grief}

Grief and mourning reactions are common in the early stages of amputation $[12,18]$. Loss of limbs often entails psychological distress equal in intensity to that in reaction to a loved one's death. Patients with a tendency to suppress their emotions may need to be encouraged to express a grief response to aid rehabilitation and ad- aptation [32].

\section{Depression}

Approximately $21 \%-35 \%$ of patients with amputation experience depressive disorder, which is higher than the rate of $10 \%-15 \%$ in the general population [33]. Depression is influenced by the premorbid function and perceived helplessness of the individual. In addition, patients with a history of major depressive disorder may develop depressive symptoms following amputation [34]. Risk factors for major depressive disorder include young age, pain, neurotic personality, and maladaptive coping skills [35]. Depression interferes with rehabilitation and adaptation; therefore, mood and level of adaptation should be appropriately evaluated at each critical period. Normal mourning reactions and hypoactive delirium can cause depression; therefore, they need to be distinguished.

\section{Anxiety}

Mild to moderate levels of anxiety are normal after amputation and during hospitalization $[36,37]$. Anxiety reactions can occur when the patient starts recognizing the loss of a limb and evaluating the effects and consequences of amputation [38]. Unfamiliar hospital environments, frequent contact with medical staff, painful treatment processes, perception of loss of control, and uncertainty about the future can increase anxiety. Anxiety can also be caused by a reaction to concerns or fear of changed abilities when reorganizing roles in the family or preparing to return to work [32].

\section{Posttraumatic stress disorder}

Traumatic events can be accompanied by intense fear and helplessness. Posttraumatic stress disorder occurs in less than 5\% of patients with surgical amputations due to chronic diseases [39], but more often in those who undergo amputation due to life-threatening situations, such as wars and accidents [40]. In stress-related disorders, reexperiences such as intrusive thoughts, recollections, and nightmares may continue, and trauma-related stimuli are actively avoided due to the intense psychological pain and increased autonomic arousal they induce [41]. These symptoms reduce the quality of life of the patient and interfere with adaptation; therefore, psychiatric intervention is needed [39].

\section{Considerations and psychological intervention by period}

Each stage of postamputation adaptation requires different aspects to be attended to and managed based on the needs and limitations of the patients. A multidisciplinary approach centered on patients and their caregivers is ideal for comprehensive rehabilitation and 
biopsychosocial management [42]. Psychological interventions should be performed as early as possible to minimize psychological distress during amputation. The considerations for intervention include postamputation conditions, physical, cognitive, psychological, social, and spiritual function, current social support system, economic situation, access to community-based resources, and current capabilities and limits [32]. In this section, we discuss the applicable psychological interventions to address these considerations during the process of amputation and rehabilitation.

\section{Preoperative stage}

If patients have time to prepare before undergoing surgery or if the pain is severe, amputation may be perceived as the end of the pain; however, various concerns and anxiety reactions may appear along with acceptance. Factors that may concern patients include the loss of limbs, relationship between family and friends, loss of function and degree of recovery, vocational skills, and costs of surgery and rehabilitation. To minimize negative psychological effects, evaluation and screening of mental health are necessary before possible amputation. Physicians should pay attention to the psychological reactions of the amputee and be aware of situations in which mental treatment is needed, and should ask for advice and refer patients to the psychiatrist. Patient concerns should be addressed, and the consequences of amputation should be discussed.

\section{Immediate postoperative stage}

Twenty-three percent of patients with amputations report the most painful time from hours to days of amputation [43]. Rapid relief of pain has a positive effect on the patient's recovery. Therefore, it is important to actively control pain during this period. Psychological reactions to anxiety and fear may appear because of concerns about safety, pain, or complications. Some experience a certain degree of numbing, which may be the effect of anesthesia and may appear in part as dealing with the trauma of loss. Mental health professionals should validate the patient's various emotional responses and support them in expressing their emotions and thoughts [44]. The patient's family is also likely to experience significant shock and acute stress responses. Families often repress their psychological difficulties or concerns to protect the patient, so it is necessary to normalize or alleviate the emotional distress of the family.

\section{In-hospital rehabilitation}

Faced with the changes caused by amputation, this is the most challenging time of change for both patients and their families. New psychological adaptation and coping skills that were not required during the acute phase may be needed. During this period, anxiety may worsen due to stress, such as fear of negative evaluation of others, fitness of prosthetics, ongoing medical conditions, and rehabilitation treatment [45]. Initially, the patient is concerned about pain and damage of appearance, but afterward, the concern gets shifted to social returning and professional adaptation. The use of maladaptive coping styles during this period may result in overcompensation, surrender, and avoidance. Overcompensation can occur in the form of self-assertion, manipulation, and obsessiveness. In the case of surrender, they may refuse rehabilitation or be obsessed with their role as a patient, and avoidance can be seen in the form of psychological and social withdrawal [46].

In the early stages of rehabilitation, motivational enhancement therapy and solution-focused brief therapy are helpful. At the beginning of the first stage of postoperative recovery, the patient may be motivated, but also daunted by concerns regarding the changes. Therefore, it is necessary to evaluate and develop the patient's motivation to understand their ambivalence and continue rehabilitation. Motivational enhancement therapy is a systematic intervention that supports a patient's motivation for change [47]. The essential point of the therapy is to create a foundation for motivation for change and to encourage confidence and hope to set and accomplish achievable goals. The basic interview principles of motivational enhancement therapy include expressing empathy, dealing with resistance, and supporting self-efficacy. Solution-focused brief therapy refers to subjects who have the resources and ability to change themselves and apply therapy to solve problems [48]. It is a goal-oriented treatment that focuses on finding realistic and viable solutions as quickly as possible, rather than carefully identifying the problem [49]. The therapist identifies the patient's positive qualities, strengths, and resources, and strengthens the patient's confidence that patients can solve the problem on their own.

In the mid- to long-term aspects of rehabilitation, cognitive behavior therapy, mindfulness meditation, and acceptance and commitment therapy (ACT) are applicable to modify maladaptive thinking and help emotional problems caused by adapting to change. Cognitive behavioral therapy (CBT) helps improve adaptation throughout the treatment and rehabilitation of patients who undergo amputation. CBT is well established as a treatment for mood disorders, and therapeutic approaches have been applied to various topics, such as body image and pain [50-52]. The goal is to help patients understand their emotions and thoughts related to their behavior and modify maladaptive cognitive patterns. Interventions such as psychoeducation, Socratic question-and-answer methods, and cognitive restructuring can expand perspectives and increase cognitive flexibility. Automatic thoughts often cause cognitive distortion, and typical cognitive distortions in patients with amputation are all-or-none thinking and catastrophizing [53]. 
Mindfulness meditation is used to reduce pain perception in chronic pain, increasing acceptance in patients with anxiety, depression, cancer, and enhancing life satisfaction [54-57]. It has the effect of reducing unpleasant sensations, thoughts, and emotions in patients through nonjudicial perception. In addition, through mindfulness meditation, objective self-observation is possible, and metacognitive insight is cultivated so that negative thoughts and feelings can be seen from a distance [58]. This improves the capacity to experience negative emotions completely as they are, reducing avoidance behavior [59].

ACT is applied to increase adaptation and psychological flexibility during the rehabilitation period after amputation. ACT emphasizes a mindfulness strategy that recognizes acceptance and presents experiences without judging them. In uncontrollable situations, acceptance increases adaptation, and commitment to new goals that contain individual values improves the purpose and meaning of actions [59]. Educating people to experience negative thoughts, emotions, and bodily sensations in a more open and flexible way can improve the quality of life and function in everyday life [60]. ACT can be applied to patients experiencing phantom limb pain or residual limb pain, as the therapeutic effect for chronic pain has been confirmed $[61,62]$.

\section{Return to daily life}

This is when the change in life due to amputation becomes apparent. Since a well-fitted prosthesis will require time to prepare, most patients may experience difficulties with daily activities without wearing a prosthesis. The difficulty of adapting to and the function of the prosthesis may lead to unexpected feelings of disappointment and distress [63]. The dynamics of the family will change, and patients and their families must adapt to their new roles. During this period, concerns surrounding occupation, social acceptance, and sexual adaptation may grow, and various degrees of regression may occur. This can be exacerbated if the patient is responsible for the family's main financial income [32]. Patients may show a tendency to rely on others or express anger when they are encouraged to live independently. Some patients perceive that they have failed to meet their economic and social responsibilities.

Interpersonal therapy can be helpful if both patients and family members are conflicted or have difficulties adapting to change. It is based on the perspective that an individual's psychological conflict is closely related to social or interpersonal problems. Rather than the psychological and unconscious meaning hidden by symptoms, it is characterized by focusing on the content of symptoms and their emotional effects, and the relevance of the problems that arise from interpersonal relationships [64]. Some important topics covered in interpersonal therapy are grief, discord, role-transition, and interpersonal sensitivity [65]. After amputation, many patients experience major changes, such as changes in their way of life, degree of dependence, support system, or employment. Interpersonal therapy can also be applied at times of loss of body parts or role changes in the family.

Group psychotherapy can be applied to support patients and their families, such as peer support groups. It can help patients improve their symptoms and self-growth and offer education and support to patients and their families [66]. It is possible to expand coping skills and improve self-management to promote adaptation through group psychotherapy with therapeutic or supportive characteristics [67]. Group psychotherapy is possible across various methods, such as face-to-face, telephone, and e-mail, and can deal with psychoeducation, problem-solving, communication, and CBT approaches [19]. Peer groups provide information on problems that patients may encounter after amputation (use of prosthesis, change of relationship, job retraining, etc.). This promotes positive adaptation and emotional support for patients and their families [68].

\section{Conclusion}

Amputation is a life-altering event in the lives of patients and their families. The psychological responses to amputation range from complex grief to anxiety, depression, and posttraumatic stress disorder. Psychological responses are affected by age, sex, level of maturity, premorbid personality traits, self-efficacy, coping mechanisms, flexibility, social support, coexistent medical disease, pain tolerance, and the urgency of amputation decisions. Difficulty in adapting postamputation can lead to problems such as low self-esteem, distorted body image, increased dependence, and social isolation; therefore, early detection and treatment of psychological problems are crucial. A multidisciplinary approach, including mental health professionals, is ideal for rehabilitation in amputated patients, focusing on the needs of patients and their caregivers. The role of mental health professionals is to normalize patients' emotions and experiences and promote psychological adaptation. Psychological intervention is recommended as the earliest opportunity to minimize psychological distress. Psychological and community-based interventions such as short-term psychotherapy, cognitive behavior therapy, mindfulness meditation, relaxation training, and group psychotherapy can be helpful. Research on the effectiveness of psychiatric interventions in patients with amputation is still limited, and additional evidence-based research with therapeutic interventions is warranted. 


\section{Notes}

\section{Conflicts of interest}

No potential conflict of interest relevant to this article was reported.

\section{Author contributions}

Conceptualization: SHJ, SHK, WSS, BHK, SHY; Data curation: SHJ; Formal analysis: SHK; Methodology, Project administration, Investigation, Resources: SHJ, WSS, BHK, HGK, SHY; Supervision: SHK; Writing-original draft: SHJ; Writing - review \& editing, SHJ, WSS, BHK, HGK, SHY.

\section{ORCID}

So-Hye Jo, https://orcid.org/0000-0001-9471-0713

Suk-Hun Kang, https://orcid.org/0000-0002-6262-3284

Wan-Seok Seo, https://orcid.org/0000-0002-5122-5360

Bon-Hoon Koo, https://orcid.org/0000-0001-9633-3835

Hye-Guem Kim, https://orcid.org/0000-0002-9677-7011

Seok-Ho Yun, https://orcid.org/0000-0002-2200-3494

\section{References}

1. Han TR, Bang MS, Jeong SG, Kang EK, Ko MH, Ko YJ, et al. Rehabilitation medicine. 6th ed. Seoul: Koonja Publishing; 2019.

2. Ziegler-Graham K, MacKenzie EJ, Ephraim PL, Travison TG, Brookmeyer R. Estimating the prevalence of limb loss in the United States: 2005 to 2050. Arch Phys Med Rehabil 2008;89: 422-9.

3. Kim SH, Lee YH, Oh WC, Hwang JH, Oh MA, Lee MK, et al. 2017 survey on disabled persons. Sejong: Ministry of Health and Welfare, Korean Institute for Health and Social Affairs; 2017.

4. Block WE, Ventur PA. A study of the psychoanalytic concept of castration anxiety in symbolically castrated amputees. Psychiatr Q 1963;37:518-26.

5. Perkins ZB, De’Ath HD, Sharp G, Tai NR. Factors affecting outcome after traumatic limb amputation. Br J Surg 2012;99(Suppl 1):75-86.

6. Horgan O, MacLachlan M. Psychosocial adjustment to lower-limb amputation: a review. Disabil Rehabil 2004;26:837-50.

7. Singh R, Ripley D, Pentland B, Todd I, Hunter J, Hutton L, et al. Depression and anxiety symptoms after lower limb amputation: the rise and fall. Clin Rehabil 2009;23:281-6.

8. Melcer T, Walker GJ, Galarneau M, Belnap B, Konoske P. Midterm health and personnel outcomes of recent combat ampu- tees. Mil Med 2010;175:147-54.

9. Mckechnie PS, John A. Anxiety and depression following traumatic limb amputation: a systematic review. Injury 2014;45: 1859-66.

10. Pezzin LE, Dillingham TR, MacKenzie EJ. Rehabilitation and the long-term outcomes of persons with trauma-related amputations. Arch Phys Med Rehabil 2000;81:292-300.

11. Armstrong DG, Lavery LA, van Houtum WH, Harkless LB. The impact of gender on amputation. J Foot Ankle Surg 1997; 36:66-9.

12. Kashani JH, Frank RG, Kashani SR, Wonderlich SA, Reid JC. Depression among amputees. J Clin Psychiatry 1983;44:256-8.

13. Atala KD, Carter BD. Pediatric limb amputation: aspects of coping and psychotherapeutic intervention. Child Psychiatry Hum Dev 1992;23:117-30.

14. Tyc VL. Psychosocial adaptation of children and adolescents with limb deficiencies: a review. Clin Psychol Rev 1992;12: 275-91.

15. Cameron K, Tebbi MD, Janis C. Long-term psychosocial outcome among cancer amputees in adolescence and early adulthood. J Psychosoc Oncol 1988;5:69-82.

16. Walters J. Coping with a leg amputation. Am J Nurs 1981;81: 1349-52.

17. Frank RG, Kashani JH, Kashani SR, Wonderlich SA, Umlauf RL, Ashkanazi GS. Psychological response to amputation as a function of age and time since amputation. Br J Psychiatry 1984;144:493-7.

18. Williamson GM, Schulz R, Bridges MW, Behan AM. Social and psychological factors in adjustment to limb amputation.J Soc Behav Pers 1994;9:249-68.

19. Rybarczyk B, Szymanski L, Nicholas JJ. Limb amputation. In: Frank RG, Elliott TR, editors. Handbook of rehabilitation psychology. Washington, DC: American Psychological Association; 2000. p. 29-47.

20. Cheung E, Alvaro R, Colotla VA. Psychological distress in workers with traumatic upper or lower-limb amputations following industrial injuries. Rehabil Psychol 2003;48:109-12.

21. Ramirez C, Menaker J. Traumatic amputations. Trauma Reports 2017;18:40-8.

22. Buchheit T, Van de Ven T, Hsia HL, McDuffie M, MacLeod DB, White W, et al. Pain phenotypes and associated clinical risk factors following traumatic amputation: results from Veterans Integrated Pain Evaluation Research (VIPER). Pain Med 2016; 17:149-61.

23. Richardson C, Glenn S, Nurmikko T, Horgan M. Incidence of phantom phenomena including phantom limb pain 6 months after major lower limb amputation in patients with peripheral 
vascular disease. Clin J Pain 2006;22:353-8.

24. Schley MT, Wilms P, Toepfner S, Schaller HP, Schmelz M, Konrad CJ, et al. Painful and nonpainful phantom and stump sensations in acute traumatic amputees. J Trauma 2008;65:858-64.

25. Arena JG, Sherman RA, Bruno GM, Smith JD. The relationship between situational stress and phantom limb pain: cross-lagged correlational data from six month pain logs. J Psychosom Res 1990;34:71-7.

26. Schoppen T, Boonstra A, GroothoffJW, de Vries J, Göeken LN, Eisma WH. Employment status, job characteristics, and work-related health experience of people with a lower limb amputation in The Netherlands. Arch Phys Med Rehabil 2001;82: 239-45.

27. Bosse MJ, MacKenzie EJ, Kellam JF, Burgess AR, Webb LX, Swiontkowski MF, et al. An analysis of outcomes of reconstruction or amputation after leg-threatening injuries. N Engl J Med 2002;347:1924-31.

28. Dougherty PJ. Long-term follow-up of unilateral transfemoral amputees from the Vietnam war. J Trauma 2003;54:718-23.

29. Rybarczyk B, Nyenhuis DL, Nicholas JJ, Cash S, Kaiser J. Body image, perceived social stigma, and the prediction of psychosocial adjustment to leg amputation. Rehabil Psychol 1995;40: 95-110.

30. Badura-Brzoza K, Matysiakiewicz J, Piegza M, Rycerski W, Niedziela U, Hese RT. Sociodemographic factors and their influence on anxiety and depression in patients after limb amputation. Psychiatr Pol 2006;40:335-45.

31. Woods L, Hevey D, Ryall N, O’Keeffe F. Sex after amputation: the relationships between sexual functioning, body image, mood and anxiety in persons with a lower limb amputation. Disabil Rehabil 2018;40:1663-70.

32. Carroll K, Edelstein JE. Prosthetics and patient management: a comprehensive clinical approach. Thorofare (NJ): Slack Inc.; 2006.

33. Williams RM, Ehde DM, Smith DG, Czerniecki JM, Hoffman AJ, Robinson LR. A two-year longitudinal study of social support following amputation. Disabil Rehabil 2004;26:862-74.

34. Bhuvaneswar CG, Epstein LA, Stern TA. Reactions to amputation: recognition and treatment. Prim Care Companion J Clin Psychiatry 2007;9:303-8.

35. Burger $\mathrm{H}$, Marincek $\mathrm{C}$. The life style of young persons after lower limb amputation caused by injury. Prosthet Orthot Int 1997; 21:35-9.

36. Shukla GD, Sahu SC, Tripathi RP, Gupta DK. A psychiatric study of amputees. Br J Psychiatry 1982;141:50-3.

37. Marshall M, Helmes E, Deathe AB. A comparison of psychosocial functioning and personality in amputee and chronic pain populations. Clin J Pain 1992;8:351-7.

38. Fitzpatrick MC. The psychologic assessment and psychosocial recovery of the patient with an amputation. Clin Orthop Relat Res 1999;(361):98-107.

39. Cavanagh SR, Shin LM, Karamouz N, Rauch SL. Psychiatric and emotional sequelae of surgical amputation. Psychosomatics 2006;47:459-64.

40. Breslau N. The epidemiology of posttraumatic stress disorder: what is the extent of the problem? J Clin Psychiatry 2001;62 (Suppl 17):16-22.

41. Opalic P, Lesic A. Investigation of psychopathological state of patients depending on specific clinical characteristics of physical trauma. Panminerva Med 2002;44:11-7.

42. Keszler MS, Wright KS, Miranda A, Hopkins MS. Multidisciplinary amputation team management of individuals with limb loss. Curr Phys Med Rehabil Rep 2020;8:118-26.

43. MacBride A, Rogers J, Whylie B, Freeman SJ. Psychosocial factors in the rehabilitation of elderly amputees. Psychosomatics 1980;21:258-61, 265.

44. Silander NC. Life-changing injuries: psychological intervention throughout the recovery process following traumatic amputations. J Health Serv Psychol 2018;44:74-8.

45. Wald J, Alvaro R. Psychological factors in work-related amputation: considerations for rehabilitation counselors. J Rehabil 2004;70:6-15.

46. Desmond DM. Coping, affective distress, and psychosocial adjustment among people with traumatic upper limb amputations. J Psychosom Res 2007;62:15-21.

47. Miller WR, Rollnick S. Motivational interviewing: preparing people to change addictive behavior. New York: Guilford Press; 1991.

48. Mireau R, Inch R. Brief solution-focused counseling: a practical effective strategy for dealing with wait lists in community-based mental health services. Soc Work 2009;54:63-70.

49. Bannink FP. Solution-focused brief therapy. J Contemp Psychother 2007;37:87-94.

50. Gorenstein EE, Papp LA. Cognitive-behavioral therapy for anxiety in the elderly. Curr Psychiatry Rep 2007;9:20-5.

51. Bhatnagar KA, Wisniewski L, Solomon M, Heinberg L. Effectiveness and feasibility of a cognitive-behavioral group intervention for body image disturbance in women with eating disorders. J Clin Psychol 2013;69:1-13.

52. Weck F, Gropalis M, Hiller W, Bleichhardt G. Effectiveness of cognitive-behavioral group therapy for patients with hypochondriasis (health anxiety). J Anxiety Disord 2015;30:1-7.

53. McGinn LK. Cognitive behavioral therapy of depression: theory, treatment, and empirical status. Am J Psychother 2000;54: 
$257-62$.

54. Kabat-Zinn J. An outpatient program in behavioral medicine for chronic pain patients based on the practice of mindfulness meditation: theoretical considerations and preliminary results. Gen Hosp Psychiatry 1982;4:33-47.

55. Rosenzweig S, Greeson JM, Reibel DK, Green JS, Jasser SA, Beasley D. Mindfulness-based stress reduction for chronic pain conditions: variation in treatment outcomes and role of home meditation practice.J Psychosom Res 2010;68:29-36.

56. Berman RL, Iris MA, Bode R, Drengenberg C. The effectiveness of an online mind-body intervention for older adults with chronic pain.J Pain 2009; 10:68-79.

57. Hofmann SG, Sawyer AT, Witt AA, Oh D. The effect of mindfulness-based therapy on anxiety and depression: a meta-analytic review.J Consult Clin Psychol 2010;78:169-83.

58. Teasdale JD, Segal ZV, Williams JM, Ridgeway VA, Soulsby JM, Lau MA. Prevention of relapse/recurrence in major depression by mindfulness-based cognitive therapy.J Consult Clin Psychol 2000;68:615-23.

59. Hayes SC, Luoma JB, Bond FW, Masuda A, Lillis J. Acceptance and commitment therapy: model, processes and outcomes. Behav Res Ther 2006;44:1-25.

60. Wicksell RK, Olsson GL, Hayes SC. Mediators of change in acceptance and commitment therapy for pediatric chronic pain.
Pain 2011;152:2792-801.

61. McCracken LM, Vowles KE, Eccleston C. Acceptance-based treatment for persons with complex, long standing chronic pain: a preliminary analysis of treatment outcome in comparison to a waiting phase. Behav Res Ther 2005;43:1335-46.

62. Vowles KE, McCracken LM, O’Brien JZ. Acceptance and values-based action in chronic pain: a three-year follow-up analysis of treatment effectiveness and process. Behav Res Ther 2011; 49:748-55.

63. Gallagher P, Maclachlan M. Adjustment to an artificial limb: a qualitative perspective. J Health Psychol 2001;6:85-100.

64. Klerman GL, Weissman MM, Rounsaville BJ, Chevron ES. Interpersonal psychotherapy of depression. New York: Basic Books; 1984.

65. Markowitz JC, Weissman MM. Interpersonal psychotherapy: principles and applications. World Psychiatry 2004;3:136-9.

66. Lee HK. Group psychotherapy: theory and practice.J Korean Neuropsychiatr Assoc 2002;41:189-200.

67. Rogers J, MacBride A, Whylie B, Freeman SJ. The use of groups in the rehabilitation of amputees. Int J Psychiatry Med $1977-$ 1978;8:243-55.

68. Mahlke CI, Krämer UM, Becker T, Bock T. Peer support in mental health services. Curr Opin Psychiatry 2014;27:276-81. 